Psychological Reports, 1966, 19, 115-118.

\title{
Teachers' Expectancies: Determinants Of Pupils' IQ Gains ${ }^{1}$
}

\author{
Robert Rosenthal \\ and \\ Lenore Jacobson \\ Harvard University \\ South San Francisco \\ Unified School District
}

\begin{abstract}
Summary - Within each of 18 classrooms, an average of $20 \%$ of the children were reported to classroom teachers as showing unusual potential for intellectual gains. Eight months later these "unusual" children (who had actually been selected at random) showed significantly greater gains in IQ than did the remaining children in the control group. These effects of teachers' expectancies operated primarily among the younger children.
\end{abstract}

1 Experiments have shown that in behavioral research employing human or animal Ss, E's expectancy can be a significant determinant of S's response (Rosenthal, 1964, in press). In studies employing animals, for example, E's led to believe that their rat Ss had been bred for superior learning ability obtained performance superior to that obtained by Es led to believe their rats had been bred for inferior learning ability (Rosenthal \& Fode, 1963; Rosenthal \& Lawson, 1964). The present study was designed to extend the generality of this finding from Es to teachers and from animal Ss to school children.

2 Flanagan (1960) has developed a nonverbal intelligence test (Tests of General A bility or TOGA) which is not explicitly dependent on such school learned skills as reading, writing, and arithmetic. The test is composed of two types of items, "verbal" and "reasoning." The "verbal" items measure the child's level of information, vocabulary, and concepts. The "reasoning" items measure the child's concept formation ability by employing abstract line drawings. Flanagan's purpose in developing the TOGA was "to provide a relatively fair measure of intelligence for all individuals, even those who have had atypical opportunities to learn" (1960, p. 6).

3 Flanagan's test was administered to all children in an elementary school, disguised as a test designed to predict academic "blooming" or intellectual gain. Within each of the six grades in the school were three classrooms, one each of children performing at above average, average, and below average levels of scholastic achievement. In each of the 18 classes an average of $20 \%$ of the children were assigned to the experimental condition. The names of these children were given to each teacher who was told that their scores on the "test for intellectual blooming" indicated that they would show unusual intellectual gains during the academic year. Actually, the children had been assigned to the experimental condition by means of a table of random numbers. The experimental treatment for these children, then, consisted of nothing more than being identified to their teachers as children who would show unusual intellectual gains.

1. This research was supported by Research Grants GS-177 and GS-714 from Division of Social Sciences of the Narional Science Foundation. We thank Dr. Paul Nielsen, Superintendent, South San Francisco Unified School District, for making this study possible; Dr. David M arlowe for his valuable advice; and MaeEvans, Nancy Johnson, John Laszlo, Susan Novick, and George Smiltens for their assistance. A more extended treatment of this material will be published by Holt, Rinehart and Winston as a chapter in a book tentatively entitled Social Class, Race, and Psychological Development. 
4 Eight months after the experimental conditions were instituted all children were retested with the same IQ test and a change score was computed for each child. Table 1 shows the mean gain in IQ points among experimental and control Ss in each of the six grades. ${ }^{1}$

Table 1. Mean Gains in IQ

\begin{tabular}{|c|c|c|c|c|c|c|c|}
\hline \multirow[t]{2}{*}{ Grade } & \multicolumn{2}{|c|}{ Controls } & \multicolumn{2}{|c|}{ Experimentals } & \multirow[t]{2}{*}{ Diff. } & \multirow[t]{2}{*}{$\mathrm{t}$} & \multirow[t]{2}{*}{$p^{\dagger}$} \\
\hline & M & $\sigma$ & M & $\sigma$ & & & \\
\hline 1 & 12.0 & 16.6 & 27.4 & 12.5 & 15.4 & 2.97 & .002 \\
\hline 2 & 7.0 & 10.0 & 16.5 & 18.6 & 9.5 & 2.28 & .02 \\
\hline 3 & 5.0 & 11.9 & 5.0 & 9.3 & 0.0 & & \\
\hline 4 & 2.2 & 13.4 & 5.6 & 11.0 & 3.4 & & \\
\hline 5 & 17.5 & 13.1 & 17.4 & 17.8 & -0.1 & & \\
\hline 6 & 10.7 & 10.0 & 10.0 & 6.5 & -0.7 & & \\
\hline Weighted M & $8.4^{*}$ & 13.5 & $12.2^{* *}$ & 15.0 & 3.8 & 2.15 & .02 \\
\hline \multicolumn{8}{|c|}{$*$ M ean number of children per grade $=42.5$} \\
\hline \multicolumn{8}{|c|}{$* *$ M ean number of children per grade $=10.8$} \\
\hline${ }^{\dagger} p$ one-taile & & & & & & & \\
\hline
\end{tabular}

5 For the school as a whole those children from whom the teachers had been led to expect greater intellectual gain showed a significantly greater gain in IQ score than did the control children ( $p=$ .02 , one-tail). Inspection of Table 1 shows that the effects of teachers' expectancies were not uniform across the six grade levels. The lower the grade level, the greater was the effect ( rho $=-.94$, $p=.02$, two-tail). It was in the first and second grades that the effects were most dramatic. The largest gain among the threefirst grade classrooms occurred for experimental Ss who gained 24.8 IQ points in excess of the gain $(+16.2)$ shown by the controls. The largest gain among the three second grade classrooms was obtained by experimental Ss who gained 18.2 IQ points in excess of the gain $(+4.3)$ shown by the controls.

6 An additionally useful way of showing the effects of teachers' expectancies on their pupils' gains in IQ is to show the percentage of experimental and control Ss achieving various magnitudes of gains. Table 2 shows such percentages for the first and second grades only. Half again as many experimental as control Ss gained at least 10 IQ points; more than twice as many gained at least 20 IQ points; and more than four times as many gained at least 30 points.

1. Therewere no differences in the effects of teachers' expectancies as a function of Ss' initial level of educational achievement; therefore, the three classrooms at each grade level were combined for Table 1. In one of the three classrooms at the fifth grade level, a portion of the IQ test was inadvertently not re-administered so that data of Table 1 are based on 17 instead of 18 classrooms. 
Table 2. Percentages of Experimental and Control Ss Gaining 10, 20, or 30 IQ Points (First and Second Grade Children).

\begin{tabular}{lcccc}
\hline IQ Gain & $\begin{array}{c}\text { Control } \\
\text { Ss* }\end{array}$ & $\begin{array}{c}\text { Experimental } \\
\text { Ss** }\end{array}$ & $\chi^{2}$ & $\mathrm{p}^{\dagger}$ \\
\hline 10 points & 49 & 79 & 4.75 & .02 \\
20 points & 19 & 47 & 5.59 & .01 \\
30 points & 5 & 21 & 3.47 & .04 \\
\hline * Total number of children $=95$. & & & \\
${ }^{* *}$ Total number of children $=19$. & & & \\
${ }^{\dagger}$ p one-tailed. & & & \\
\hline
\end{tabular}

7 An important question was whether the gains of the experimental Ss were made at the expense of the control Ss. Tables 1 and 2 show that control Ss made substantial gains in IQ though they were smaller than the gains made by experimental Ss. Better evidence for the proposition that gains by experimental Ss were not made at the expense of control Ss comes from the positive correlation between gains made by experimental and control Ss. Over the 17 classrooms in which the comparison was possible, those in which experimental Ss madegreater gains tended also to be the ones where control Ss made greater gains ( $r h o=.57, p=.02$, two-tail).

8 Retesting of the children's IQ had been done in classroom groups by the children's own teacher. ${ }^{1}$ The question arose, therefore, whether the greater gain in IQ of the experimental children might have been due to the teacher's differential behavior toward them during the retesting. To help answer this question three of the classes were retested by a school administrator not attached to the particular school. She did not know which children were in the experimental condition. Results based on her retesting of the children were not significantly different from the results based on the children's own teachers' retesting. In fact, there was a tendency for the results of her retesting to yield even larger effects of teachers' expectancies. It appears unlikely, then, that the greater IQ gains made by children from whom greater gains were expected could be attributed to the effect of the behavior of the teacher while she served as an examiner.

9 Thereare a number of possible explanations of the finding that teachers' expectancy effects operated primarily at the lower grade levels, including: (a) Younger children have less well-established reputations so that the creation of expectations about their performance would be morecredible. (b) Younger children may be more susceptible to the unintended social influence exerted by the expectation of their teacher. (c) Younger children may be more recent arrivals in the school's neighborhood and may differ from the older children in characteristics other than age. (d) Teachers of lower grades may differ from teachers of higher grades on a variety of dimensions which are correlated with the effectiveness of the unintentional communication of expectancies.

1. Scoring of the tests was done by the investigators, not by the teachers. 
10 The most important question which remains is that which asks how a teacher's expectation becomes translated into behavior in such a way as to elicit the expected pupil behavior. Prior research on the unintentional communication of expectancies in experimentally more carefully controlled interactions suggests that this question will not be easily answered ( Rosenthal, in press)

11 But, regardless of the mechanism involved, there are important substantive and methodological implications of these findings which will be discussed in detail elsewhere. For now, one example, in question form, will do: How much of the improvement in intellectual performance attributed to the contemporary educational programs is due to the content and methods of the programs and how much is due to the favorable expectancies of the teachers and administrators involved? Experimental designs to answer such questions are available (Rosenthal, in press) and in view of the psychological, social and economic importance of these programs the use of such designs seems strongly indicated.

\section{References}

Flanagan, J. C. Tests of general ability: technical report. Chicago, III: Science Resea rch Associates, 1960.

Rosenthal, R. The effect of the experimenter on the results of psychological research. In B. A. Maher (Ed. ) Progress in experimental personality research. Vol. 1. New York: Academic Press, 1964. Pp. 79-11

Rosenthal, R. Experimenter effects in behavioral research. New York: AppletonCentury-Crofts, in press.

Rosenthal, R., \& Fode, K. L. The effect of experimenter bias on the performance of the al bino rat. Behavioral Science, 1963, 8, 183-189.

Rosenthal, R., \& Lawson, R. A longitudinal study of the effects of experimenter bias on the operant learning of laboratory rats. Journal of Psychiatric Research, 1964, 2, 61-72.

Accepted May 10, 1966. 